Sen's editorial,' may well be due to tuberculosis; rates there now are comparable with those in the United Kingdom during part of the last century. Tuberculosis is, to a great extent, a disease of social deprivation, and thus Sen's point is valid. For some reason, however, young females have a higher mortality from tuberculosis than their male peers; this phenomenon is not yet understood and may account for at least some of Sen's missing women.

Tuberculosis Research Unit,

P D O DAVIES

Tuberculosis Research Unit,

South Liverpool Chest Clinic

Liverpool L15 2HE

1 Sen A. Missing women. BMf 1992;304:587-8. (7 March.)

\section{Tibial fixation}

SIR, - The tibial hardware shown in a radiograph on Minerva's page' is almost certainly a Parham's band, well described as "the sort of clamp used to tie up electrical cables." I remember being shown it in a surgical instrument seminar as a medical student at Aberdeen Royal Infirmary in the late 1930s. One elderly surgeon still used it for oblique shaft fractures in long bones, but most of our teachers regarded it as a museum piece.

E G HARDY

Tarporley,

Cheshire CW6 0HD

1 Somerville DW. [Tibial $x$ ray.] BMf 1992;304:650. (7 March.)

\section{Starting date of house officer posts}

SIR, - It always strikes me as inefficient and dangerous that house officer posts start on the first day of the month, even if this falls on a Friday or a weekend, when there is likely to be least supervision of these inexperienced doctors.

Since there is more support from middle grade doctors and consultants during a weekday and since we tend to think about the week as running from Monday to Sunday, would it not be much more sensible to have house officers starting their posts on, say, the Monday after the first day of the relevant month? Bank holiday Mondays would not interfere with this plan for February and August, when the bulk of job changes occur, but would be awkward in May. No doubt local arrangementments could be made in that case.

This plan has met with approval from the paediatric department at this hospital, but we would be unable to introduce it without cooperation from other hospitals from which doctors are likely to come since this may introduce a gap or overlap between appointments. Hence I write to you as a wider forum for suggesting this simple but useful change in the employment of house officers.

A KAISER

St Thomas's Hospital

London SEI 7EH

SIR, -1 February has been and gone; hospitals around the country have coped with the influx of new doctors. For a good proportion of the doctors who have changed jobs the start of February will have meant a change of specialty or of hospital, or both.

1 February was a Saturday. I doubt that many hospitals managed to run an induction course that day, so many juniors will have found themselves on call for a strange unit in a strange hospital, relying on the good will of those around them to cope with the routine and emergency tasks put before them.
Little wonder that mortality figures in hospitals show a small blip in February and August.

The safety of patients aside, the Saturday changeover had one advantage. Apart from those poor souls who spent the weekend on duty, the rest of us had the whole weekend in which to move our home. Admittedly, few doctors move an appreciable distance between jobs, but for them the usual state of affairs - when the first of the month falls in the middle of the week - is to finish in one hospital at (they hope) $5 \mathrm{pm}$ and have just 16 hours before starting the new job elsewhere. It is difficult to move home, spouse, and two small children from Plymouth to Glasgow on a Tuesday night, but somewhere out there will be a junior doctor who had to manage it.

There is a better way. Why could we not all start new jobs on the first Monday of the month? This would guarantee that the new juniors arriving at a department would have five full days to get used to things before they had to cope with a weekend on call, the weekend being the time when the average hospital provides the least back up for junior staff. It would allow most doctors the whole weekend in which to move. Induction courses would always be on a Monday, making planning simpler. Domestic staff would have more time to clean rooms. Staff would arrive with time to spare and might even look around the wards to find out what awaited them on Monday morning.

It is time that this illogical, inconsiderate, and inconvenient tradition was replaced. A single directive from the General Medical Council or Department of Health could have the new system in force in time for August: why not?

DAVID R TOOTH

\section{Good Hope Hospital,}

West Midlands B75 7RR

\section{Outcome measures should be relevant}

SIR, - The measurement of health outcomes is necessary for research, the assessment of innovations in services, and audit of established services. This is especially true for chronic conditions, for which traditional measures of success or failure in management, such as death or cure rates, are inappropriate, and for strategic management, in which the relative effects of widely differing conditions and interventions must be compared.

Alison Frater and David Costain's editorial is to be welcomed for reiterating these points, ${ }^{1}$ but caution is needed. The medical outcomes study short-form general health survey, which Frater and Costain describe, is only one of a growing number of generic general health measures. ${ }^{2}$ Although it is able to discriminate between different medical conditions, a more pressing need is to show sensitivity to change due to intervention.

The scale in the medical outcomes study describes a "profile" with six different scores being given for physical functioning, role functioning, mental health, and so on. The purchaser who wants to compare psychiatric inpatient care with hip replacement operations may have to trade of effects in different dimensions. Is a 10 point improvement in social functioning better than a five point improvement in health perceptions? A valid summary score to resolve this remains elusive, for this or any other general health scale.

Outcome measures need to be relevant to the objectives of the intervention. The four point New York Heart Association classification was used successfully to show improved functional abilities in the cooperative north Scandinavian enalapril survival study (a trial of enalapril in heart failure) but would have been inadequate for a trial of a new antidepressant agent. An unsuitable generic scale used in a trial of NHS nursing homes failed to detect important differences shown by more suitable scales. ${ }^{*}$ The management of many chronic medical conditions depends on rehabilitation. This entails reducing disability by helping patients to reacquire lost skills and teaching new ones, providing aids and adapting patients' environment, psychological readjustment, involving the family and carers, and appropriate resettlement in suitable accommodation. These activities can be summarised as the reduction of handicap, the disadvantage that results from ill health.' No adequate measure of handicap exists. Generic outcome measures may be insensitive to the effects of such interventions or may be only proxy measures while in fact measuring depression. ${ }^{\circ}$

Measurement of health outcomes will be a useful advance so long as valid, reliable, sensitive, and relevant scales are used. Some disease specific scales will remain useful.

ROWAN H HARWOOD PATRICK H GOMPERTZ SHAH EBRAHIM

Department of Health Care of the Elderly,

Royal London Hospital,

London E1 4DG

1 Frater A, Costain D. Any better? Outcome measures in medical udit. BMf 1992;304:519-20. (29 February.)

2 McDowell I, Newell C. Measuring health. A guide to rating scales and questionnaires. New York: Oxford University Press, 1987. 3 CONSENSUS Trial Study Group. Effects of enalapril on mortality in severe congestive heart failure. $N \mathrm{Engl} F \mathrm{Med}$ 1987;316:1429-35

4 Donaldson C, Atkinson A, Bond J, Wright K. QALYs and long term care for elderly people in the UK: scales for assessment of quality of life. Age Ageing 1988;17:379-87.

World Health Organisation. The international classification of impairments, disabilities and handicaps. Geneva: WHO, 1980.

6 Ebrahim S, Barer D, Nouri F. Use of the Notringham healt profile with patients after a stroke $\mathcal{F}$ Epidemiol Community Health 1986;40:166-9.

\section{Rationing health care}

SIR,-Contrary to Chris Heginbotham's assertion the proportion of gross domestic product spent on health care has not increased steadily in all countries of the Organisation for Economic Cooperation and Development.

Three countries (Sweden, New Zealand, and Denmark) were able to reduce the percentage of their gross domestic product spent on health care between 1980 and 1987, and two other countries (Italy and Spain) increased their spending by only 0.1 percentage units, which is less than the mean increase of 0.5 percentage units according to Heginbotham's figures (table I). Was this achieved through rationing health care or another way, such as changed accounting?

Although in 1987 the United States had the highest spending on health care in relation to its gross domestic product, between 1980 and 1987 the relative increase in spending was greater in Greece and Iceland than in the United States. If the United States and Greece are considered as statistical outliers then the spread in health care expenditure is narrow and has changed little, from 5.9 to 9.5 in 1980 to 6.0 to 9.0 in 1987 . Heginbotham draws attention to the danger of relying on percentage of gross domestic product, and in his table II (where, oddly, the figures for Sweden are missing) excluding outliers the "medical care purchasing power parity" centres around $\$ 1000$. Thus, the optimal spending on health care seems to be $7-9 \%$ of gross domestic product or $\$ 1000$ medical care purchasing power in 1980's value.

The cost of caring for an individual rises greatly in the higher age groups. Shortsightedly, the income tax raised in the halcyon days of the ' $50 \mathrm{~s}$ and ' 60 s when the British "never had it so good" was used to correct accumulated neglect from the years of the depression and the war; none was invested for the future. Hence, the problem facing the health service is that it has been using and still 